\title{
A Greek tragedy of our time? Institutional and financial dimension of Health Promotion for Odder People in Greece
}

\author{
Milena Pavlova ${ }^{1}$, Yannis Skalkidis², Wim Groot ${ }^{3}$, \\ Agnieszka Sowa ${ }^{4}$, Stanisława Golinowska ${ }^{4,5}$
}

\begin{abstract}
${ }^{1}$ Department of Health Services Research, CAPHRI, Maastricht University Medical Center, Faculty of Health, Medicine and Life Sciences, Maastricht University, Maastricht, the Netherlands; ${ }^{2}$ NKUA - National and Kapodistrian University of Athens, Medical School, Goudi, Athens, Greece; ${ }^{3}$ Department of Health Services Research, CAPHRI, Maastricht University Medical Center, Faculty of Health, Medicine and Life Sciences, Top Institute Evidence-Based Education Research (TIER), Maastricht University, Maastricht, the Netherlands; ${ }^{4}$ Department of Social Policy, Institute of Labour and Social Studies, Warsaw, Poland; ${ }^{5}$ Institute of Public Health, Faculty of Health Sciences, Jagiellonian University Medical College, Cracow, Poland
\end{abstract}

Address for correspondence: Milena Pavlova, Department of Health Services Research, Faculty of Health, Medicine and Life Sciences, Maastricht University, PO Box 616, 6200 MD Maastricht, the Netherlands, +31-43-3881705, m.pavlova@maastrichtuniversity.nl

\section{Authors contribution}

MP and SG designed the concept, MP carried out the data collection and analysis, and drafted the paper, AS commented on the paper and provided additional data, YS, WG and SG reviewed the draft and provided comments for the final version. All authors read and approved the final version submitted.

\section{Abstract}

Despite the numerous legislative documents and public health institutions in Greece, the country lacks a comprehensive and robust long-term policy perspective in the public health area. The traditionally higher priority attached to curative care than to public health actions, is the major reason of the shortcomings. This country report draws upon several national reports focused on the Greek health system, and other country-specific sources in order to outline the major institutional and financing challenges for health promotion in Greece, and specifically health promotion for older adults. The paper is based on the method of narrative literature review. The findings show that health promotion actions for elderly persons do take place in Greece but mainly in urban areas and/or within the framework of EU-funded projects. Government efforts are required to stimulate coordinated public health interventions at the local level focusing on the positive effects of health promotion. The health promotion programs that are successfully implemented, should receive the necessary government support to assure their long-term sustainability.

Key words: public health, health promotion, older adults, health policy, Greece

\section{Introduction}

The public health concept has been interwoven in many laws and government regulations in Greece [1]. Numerous public health institutions have been also established (e.g. the Central Health Council, the National
Council of Public Health, the Health Region Authorities). Yet, a long-term policy perspective in the public health area is still lacking, and coordinated health promotion actions are practically absent. The traditionally higher priority attached to curative care than to public health actions, is the major reason of the shortcomings. This 
paper reviews key national reports focused on the Greek health system, and other country-specific sources in order to outline the major institutional and financing challenges for health promotion in Greece, and specifically for health promotion for older adults. The method of narrative literature review is used. The paper has the form of a country report and targets the decision-makers in Greece, as well as those elsewhere in Europe, who would like to get insights in the public health developments in Greece.

\section{Legislation on public health and health promotion generally and for older population}

Greece introduced legal provisions in the area of public health already in the nineteenth and early twentieth centuries but only with regard to communicable diseases and without an effective implementation of the legislation in practice [1]. In this period, the Ministry of Hygiene and Social Welfare was established (Law 748/1917). However, the public health measures introduced by the ministry were limited to vaccination and sanitation interventions. Furthermore, measures for health and safety at work (Law 3934/1911 and Law 551/1915), establishment of mutual societies (Law 281/1914) and obligatory insurance of employees (Law 2868/1922) were introduced with a limited success [2].

In the mid-twentieth century, the legal and regulatory actions focused on medical care. There were only sporadic public health actions mostly as a response to tuberculosis and sexually transmitted diseases. During the dictatorship period (1967-1974), the first attempt to organize a comprehensive health care system was observed, although this objective was not successfully achieved. Following the democratic changes in 1974, the need for health care reforms became evident and was acknowledged as a major government priority. However, due to the political and medical societies' opposition, the numerous reform proposals were never implemented [2].

Only in 1983, an effective legislation for the establishment of the Greek National Health System (Law 1397/83) was passed. The ambition was to create a universal coverage and equal access to health services. The state was expected to be fully responsible for the provision of health services to the population [2]. Nevertheless, the public health actions did not receive much attention in the twentieth century. For the first time in 2003, in the anticipation of the 2004 Athens Olympic Games, the Greek government seriously attempted to control infectious diseases effectively. It should be mentioned however that this effort did not include a well-conceptualized vision and had many shortcomings, including the lack of clarity about jurisdictional boundaries, lines of command, and procedural requirements [1].

In 2005, a new law was passed (Law 3370), which is still active and regulates the public health actions for preventing diseases, protecting and promoting health, lengthening life expectancy and improving quality of life. The law declares that disease prevention and health promotion are the main functions of public health [3]. Together with this law, the General Secretariat for Public Health and the General Directorate for Public Health were established at the Ministry of Health and Social Solidarity. Their direct responsibility is to implement measures within the framework of the National Action Plan for Public Health, to inspect public health agencies and to monitor and supervise the implementation of EU policies [2].

Despite this new legislation, public health services in Greece remain of low priority compared to curative care. Also, public health professionals have a rather low status within the National Health System, which results in understaffed public health facilities.

Nevertheless, some positive changes are observed, namely health promotion and health education are increasingly perceived as essential for the population health. The perceived importance of a healthy lifestyle is also growing among the Greek population [2]. More policy efforts are however needed to assure a modern and comprehensive system of public health services focused on health determinants and needs of vulnerable groups (for example the elderly and disabled). Such system is still absent in the country [1].

\section{Health system indicators}

The performance of the Greek National Health System has been often criticized [4]. The following areas are mentioned as most problematic: poor administration, low productivity and inadequate primary care. Guided by the objective to deal with these drawbacks, the government introduced major health reforms in 2000-2004. The reforms focused on decentralization, creation of a unified social insurance system, establishment of new management structures, organization of a primary care system, and strengthening public health and health promotion $[2,4]$. These reforms were however abolished after the elections of 2004.

The most recent health care reforms, since 2005, have aimed to assure the financial viability of the health system in the short term and its sustainability in the long term. Nevertheless, the reforms have been criticized for their controversy, clientelism and political influence on the health administration [2]. Overall, a comprehensive and universal health system has not yet been established in Greece. The achievement of this objective has become even more difficult with the start of the latest economic crisis. There is an overall lack of sufficient buildings, basic technological equipment and computerization, as well as a lack of a fair distribution of the limited public health resources and understaffing. This contributes to poor quality and inequalities in access, especially for the elderly persons. Also, the system organizational culture is dominated by clinical medicine and hospital services, without an adequate attention and support for public health activities. It is therefore not surprising that the percentage of Gross Domestic Product (GDP) that Greece allocates to public health is rather low (see Table I). 


\begin{tabular}{|l|}
\hline Overall indicators: \\
Total health expenditure per capita: 1438.78 Euro \\
Total health expenditure as \% of GDP: $8.75 \%$ \\
\hline Selected functions as \% of total health expenditure: \\
Curative care: $58.75 \%$ \\
Pharmaceuticals and other medical non-durable goods: $29.28 \%$ \\
Preventive care: $1.08 \%$ \\
Epidemiological surveillance and risk, and disease control pro- \\
grams: $0.50 \%$ \\
Information, education and counseling programs: $0.47 \%$ \\
Immunization programs: $0.08 \%$ \\
Healthy condition monitoring programs: $0.02 \%$ \\
\hline
\end{tabular}

Table I. Health system indicators - Greece (data for 2013). Source: Based on the Eurostat database.

\section{Population aging indicators}

The life expectancy in Greece rose from 74.6 years for males and 79.4 for females in 1990 to 75.4 and 80.5 respectively in 2000 [5], and further on to 78.9 and 84.1 respectively in 2014/2015 (see Table II). Besides, in 2000 , the population aged over 65 was only $16.6 \%$, while in $2014 / 2015$ it was already $20.9 \%$. The estimations suggest that the share of older persons $(65+)$ will reach $31.5 \%$ of the general population in 2050 [5]. The increased life expectancy, combined with the increased population ageing, has important implications. In particular, fewer people of productive age will support the increasing demands on the Greek health and pension systems. It is therefore essential to further develop health promotion and prevention in order to help older adults to live longer and in good health. It is also essential to secure more resources for health promotion for example by reducing unnecessary medical expenditure.

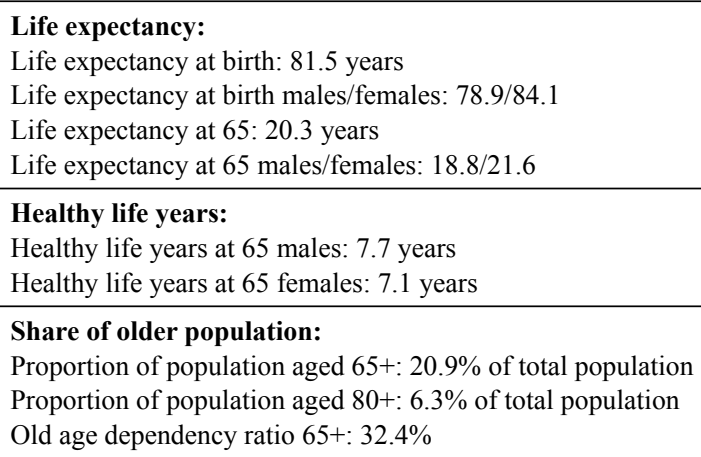

Table II. Population ageing indicators - Greece (data for 2014/2015)

Source: Based on the Eurostat database.

\section{Health status of older population}

In Greece, premature mortality was substantially reduced during the period 1980-2007 (by $43.2 \%$ ). It is recognized that the establishment of the National Health System had a positive effect on the health indicators in the country. Although Greece ranks relatively high based on the population health status, there are many healthrelated challenges to be addressed, including problematic driving behavior as well as drinking, smoking and poor eating habits of the population [2]. In fact, the group of elderly in Greece appears to be among the most health illiterate European population groups [6]. The prevalence of mental health problems (e.g. depression) among elderly $[7,8]$ as well as the problem of a high rate of drug use and polypharmacy (large pharmaceutical consumption) in elderly is also acknowledged [9]. Moreover, the consequences of the global financial recession and the subsequent austerity measures had not only an economic impact but also negative consequences for the national health sector and social services, including public health services [10]. The government was unable to provide the necessary support for these services [11], which may have further contributed to the declining health status of the population, including that of older persons (see Table III).

\author{
Prevalence of long-standing illness: \\ Age group 65-74 males/females: $45.5 \% / 45.9 \%$ \\ Age group 75-84 males/females: 59.5\%/69.4\% \\ Age group $85+$ males/females: $69.3 \% / 79.1 \%$ \\ Self-perceived long-standing limitations in usual activities due \\ to health problems: \\ Age group 65-74 males/females: $48.8 \% / 51.4 \%$ \\ Age group 75-84 males/females: 64.0\%/74.5\% \\ Age group $85+$ males/females: $77.4 \% / 87.2 \%$
}

Table III. Health status of older population - Greece (data for 2014).

Source: Based on the Eurostat and EU-SILC databases.

\section{Potential sources of funding public health and health promotion activities}

The public health system in Greece is highly centralized and primarily funded through government resources (see Table IV). The state public health facilities mainly provide epidemiological monitoring and infectious disease control as well as environmental health control, health promotion and disease prevention at community level [2]. They are funded through annual budgets. However, the total budget for public health is not dedicated and specific. The general government budget for health care refers to both curative services and public health actions. Given the predominantly medical culture in the health sector and the lack of a health promotion vision in the country, most of the health resources are allocated to curative care leaving the public health activities with irregular funding. The current investments in long-term plans to improve the population health are insufficient [3].

Theoretically, the Social Insurance Institute (IKA), which is the largest social health insurance fund in Greece, provides its members with a wide range of preventive, diagnostic, curative and rehabilitation services, such as general medical care for the adult population and 
elderly persons, health promotion, occupational medicine, first aid, vaccinations, epidemiological research, social care and pharmacy services. Thus, basic public health services are formally included in the IKA health insurance package [12]. But in practice, this is limited to prescriptions, referrals to secondary health care services and high-cost examinations (mainly for elderly people). In some cases, IKA organizes holiday trips and spa accommodation for elderly persons [2]. No health promotion services are explicitly mentioned for IKA or other social health insurance funds.

All visits to physicians and diagnostic centers that provide public health services under a social insurance fund, are free of charge for the patient. However, due to access- and quality-related problems in the public system, patients often seek primary care (including basic public health services) at the private sector. In this case, the patients pay the full user fee. There is coinsurance for diagnostic and laboratory tests (from 0 to $30 \%$ ) depending on the insurance fund and the status of the diagnostic center [2].

Private health insurance in Greece plays a relatively minor role in the overall health system, since it offers coverage to no more than $12 \%$ of the population [2]. Private insurance packages include minor health promotion and prevention services, such as health checks and diagnostics.

Some public health initiatives are funded through EU resources, including the EU Structural Funds [13]. However, the use of these funds is uncoordinated, inefficient and characterized with overlaps. The objectives of the EU-Funded public health programs are also focused on the EU priorities and not necessarily on the real population needs in Greece [3].

\section{Institutitionala analysis (sectors, organizations and their functions)}

The Ministry of Health is the main decision-makers in the public health area in Greece and is directly accountable for the public health policy in the country [2]. Several directorates and departments of the Ministry of Health are engaged in the development of public health programs, including health promotion and prevention programs. This includes the General Secretary for Public Health at the Ministry of Health, the General Directorate for Public Health and Quality of Life, the Directorate for Public Hygiene, the Directorate for Nutrition, and the Directorate for Dependence. Apart from that, the governance and regulation of public health activities involve the Central Health Council, the National Council of Public Health, the National Organization for Healthcare Provision, and the National Primary Healthcare Network. All these institutions assume different tasks and responsibilities related to public health and health promotion policies in particular [3].

Seven Health Region Authorities are responsible for implementing national public health priorities at the regional level as well as for coordinating regional activities. They also advise the Ministry of Health on public health measures. The Central Council of Health Regions coordinates the work of the Health Region Administrations, as well as their cooperation with the ministry $[2,3]$.

At the prefectural level, the public health departments of the Prefectural Authorities have the responsibility to implement immunization and preventive medicine programs, while at the local level, municipalities are responsible for managing public health programs related to the

\begin{tabular}{|c|c|c|}
\hline Source of funding & Beneficiary & Additional Comments \\
\hline $\begin{array}{l}\text { Taxes: } \\
\text { Including } \\
\text { - general taxes }\end{array}$ & $\begin{array}{l}\text { The general public or specific target group who } \\
\text { uses the public health services }\end{array}$ & $\begin{array}{l}\text { There is no general tax revenue specifically allocated } \\
\text { to public health and therefore, public health competes } \\
\text { with curative care, which receives a higher priority in the } \\
\text { distribution of resources. }\end{array}$ \\
\hline $\begin{array}{l}\text { Health insurance premiums } \\
\text { Including } \\
\text { - social insurance } \\
\text { - private insurance }\end{array}$ & $\begin{array}{l}\text { Socially insured patients who use public health } \\
\text { services provided by GPs or diagnostic centers } \\
\text { Adults who have extra private insurance }\end{array}$ & $\begin{array}{l}\text { Patients do not need to pay for physician services provided } \\
\text { under a health insurance scheme during the regular work } \\
\text { hours. } \\
\text { But there is } 0-30 \% \text { coinsurance for diagnostics. } \\
\text { The role of private insurance is minor. }\end{array}$ \\
\hline Other public institutions: & $\begin{array}{l}\text { Beneficiaries of services related to public } \\
\text { health provided by other ministries }\end{array}$ & $\begin{array}{l}\text { Other ministries include for example the Ministry of } \\
\text { Labor, Social Security and Welfare. }\end{array}$ \\
\hline \multicolumn{3}{|l|}{ Other sources: } \\
\hline Households & Private sector patients & Full fees in the private sector. \\
\hline Foreign & $\begin{array}{l}\text { International research projects and EU funds } \\
\text { beneficiaries }\end{array}$ & $\begin{array}{l}\text { Focused on EU priorities and not necessarily on the real } \\
\text { needs of the Greek populations. }\end{array}$ \\
\hline Others & Beneficiaries of NGOs initiatives & $\begin{array}{l}\text { NGOs include community organizations and associations } \\
\text { of patients with chronic disease. }\end{array}$ \\
\hline
\end{tabular}

Table IV. Sources of public health funding in Greece.

Source: Based on own review of literature. 
provision of primary care, health prevention and promotion services. Many of these programs are delivered in rural health centers and the IKA health centers in urban areas. This is because the municipal public health services are underdeveloped in Greece [2].

Several NGOs implement primary and preventive health programs for refugees and socially disadvantaged population groups. The Ministry of Health supervises the work of NGOs active in the field of public health. In addition, the Ministry of Health cooperates with the Ministry of Labor, Social Security and Welfare, and the Ministry of Employment and Social Protection with regard to programs on occupational safety and health that are implemented by the latter ministry [3].

The coordination between the different bodies involved in the implementation of primary prevention and health promotion policies and programs is weak [2, 3]. Health promotion and primary prevention programs are only evaluated if they fall within the framework of a funded research project. There are insufficient resources and capacity to undertake more routine analyses of health promotion and primary prevention activities. There are no multidisciplinary teams in place to address health promotion and primary prevention. Also, there are no structures and mechanisms in place to respond to the needs and priorities of disadvantaged or vulnerable groups. For the case of elderly persons, the coordination between the health sector, social care sector and care services for elderly persons is still not adequate [3].

\section{HP4OP - Health Promotion for Odder People (examples of good practices)}

An important aspect of the health promotion initiatives for elderly persons in Greece, is that they often take place within the Open Care Centers for Older People (KAPIs). The members of these centers are older persons (60+ years) who mostly choose to join the centers due entertainment and/or possibility for a companionship [14]. Health and social care professionals, such as nurses, social workers, physiotherapists, occupational therapists, home care assistants are usually working at these centers. They have the task to promote a healthy lifestyle among the members. Such centers are established throughout the entire country (more than 450 centers) and are very well accepted by the elderly persons [5]. The centers are managed and funded by the local authorities. Sometimes, elderly members are invited to participate in the administration.

Although there is no national mechanism to identify good practices in Greece [3], several of the health promotion initiatives implemented in the KAPIs are recognized to be well designed and effectively implemented [3, 5]:

- "Action Programme for Older People" is focused on the maintenance and improvement of mobility, autonomy and self-care among older persons, and it aims to achieve this through physical exercises. The program emerged in 1997 in one municipality in the city of Athens based on previous projects coordinated by the General Secretariat for Sports that were im- plemented in the KAPIs in different municipalities. The main funding of the program comes from private contributions, while the management is in the hands of the local Primary Health Care Services. The target group comprises people above the age of 60 years old. The program is implemented in two phases: (a) provision of information through lectures and discussions about health related problems, and the role of exercises in the improvement of health; (b) a set of physical exercises in a special sport room and outdoor athletic areas. Two program sessions per week are offered and the duration of each session is 45 minutes. The participants' physical state and mobility is evaluated annually, including the joint functional ability and mobility, the improvement of neuromuscular control on the movements, body balance, health-related habits and the need of physiotherapy. The evaluation of the entire project takes place every 5 years and so far, it has shown positive effects.

- "The Involvement, and the Role of Older Volunteers in Promoting Healthy Diet for the Prevention of Cardiovascular Diseases" is a program based on the Senior Health Mentoring concept. The program was implemented in KAPIs in two municipalities in Athens and received funding from the European Commission and Greek national funds. The program was designed as a pilot study to test the involvement of older people in health promotion activities through the reinforcement of existing experience and knowledge. The first phase of the program included the training of older adults in teaching and communication principles, as well as in contemporary nutritional principles based on the Mediterranean diet. The second phase of the program involved the spread of knowledge gained by the trained adults among other KAPI members. The evaluation of the program demonstrated its success in terms of participants' satisfaction, changes in their own lifestyle, useful feedback and knowledge sharing. As a results of the program, an information package was produced for all KAPIs in the country. This information package is still in use.

- "The Role of Health Education in Improving Compliance for the Prevention of Cardiovascular Diseases" is a program focused on the access to preventive services and adoption of a healthier lifestyle. The program took place in two KAPIs in Athens and was co-financed by the European Commission and Greek national funds. The key objective of the program was to provide health education sessions to increase the awareness of the importance of preventive services and healthier lifestyle for the reduction of cardiovascular risks among older people. The results of the evaluation of this program showed a successful reduction of the participants' body weight, healthier habits, more regular measurement of blood pressure and glucose, and more regular visits to the physician. It should be mentioned however that the participation in lifelong learning and other work-related education activities in Greece is rather low, particularly for those aged 55-64, compared to other countries in the EU 
[13]. Overall, such activities are rare and dependent on external funding (e.g. through EU projects) as well as on the good will of the actors involved (employers and employees). These activities also lack a systemic support (incl. financial support) by the central government, which indicates that they are not a priority for the policy-makers in Greece [13]. Direct financial-incentives programs related to health promotion that target the group of elderly persons are also absent in Greece.

\section{National health promotion policy generally and addressed at the older people}

In Greece, the health policies, including health promotion policies for elderly persons, are the responsibility of the Ministry of Health, which is the main health policy-making authority [2]. The ministry decides on health policy issues and national health strategies, sets priorities, determines the funding for activities, allocates resources, proposes legislative changes and undertakes the implementation of laws and/or reforms [3]. Despite this responsibility, so far, the ministry has not succeeded to develop a national health target program for setting priorities. The same holds for a national plan for the implementation of 'Health in All Policies'.

On the positive side, a public consultation process took place during 2007-2008, resulting in the development of the National Action Plan for Public Health for the period 2008-2013. This plan emphasized the importance to deal with health hazards such as infectious and rare diseases, drugs, dietary disorders, smoking, environmental hazards, alcohol, dental health, etc. However, only a few measures have been implemented. For example, the ban of smoking in public places [2] has been legislated but not really/fully implemented in practice. The economic challenge that faced the country in this period, was one reason for this policy failure.

In 2012, the Health in Action Initiative (2012) was adopted. It aims to create the conditions for a more effective health system that meets the international standards and public health targets [3]. Nevertheless, the lasting economic crisis remains a hurdle for its implementation.

Overall, the health challenges in Greece mainly remain the subject of academic discussions and EU-funded projects. Academic advisers to the Ministry of Health, as well as representatives of major NGOs have had hitherto a negligible impact on policy. Moreover, policies and programs implemented in sectors other than health, do not acknowledge their potential health impacts. In fact, there are no mechanisms in place to ensure the coordination and effective implementation of cross-sectoral interventions addressed to the prevention of chronic disease and their risk factors [3].

The failure of the Greek government to implement a successful strategy for public health despite its intentions declared in the laws, is explained by several major barriers [3]:

- the strong focus on curative care as well as the chronic lack of disease prevention and health promotion vision since the establishment of the National Health Care system in the 1980s;

- the fragmented and uncoordinated institutions in the public health area, which makes it difficult to implement national-level policy and impose them at the local level;

- the lack of knowledge and experience within the public health institutions on health determinants and underlying causes of mortality and morbidity;

- the significant shortage of financial resources for public health due to the economic crisis but also due to the low priority attached to public health and health promotion.

The factors listed above, also explain the lack of strategic documents on the development and implementation of health promotion programs for elderly persons in the country.

\section{Conclusions and recommendations}

The findings of this narrative literature review confirm that despite the numerous legislative documents and public health institutions in Greece, the country lacks a long-term policy perspective in the public health area. The traditionally higher priority attached to curative care over public health actions, is the major reason for this drawback. As a result, the public health resources, and in particular resources for health promotion and primary prevention, are insufficient and their level is unstable [3]. The processes of allocating funding to primary prevention and health promotion are not transparent, and are influenced by political interests [2]. The separation of the public health budget from the budget for curative care is the first essential step in strengthening the public health services in the country, including health promotion actions for elderly persons. However, the potential effects of such separation need to be first investigated in order to identify an effective reform implementation strategy.

The review also demonstrates that overall, health promotion actions for elderly persons do take place in Greece but mainly within the KAPIs, in urban areas and/or within the framework of EU-funded projects. Government efforts are required to stimulate coordinated information campaigns focusing on the positive effects of health promotion and disease prevention for elderly persons, but also for younger persons. Such campaigns should be designed based on empirical studies carried out among the targeted age groups. The participation in the KAPIs needs also to be further investigated to identify groups whose participation needs to be stimulated given the expected positive effects mentioned in the publications reviewed [14]. Given the specific geographic features of Greece (many islands and continental main land), the difference in life style between older islanders and their main-land counterparts should also be taken into account [15]. A national health promotion strategy should be developed and enforced at local levels. The health promotion programs that are successfully implemented, should receive the necessary government support to assure their long-term sustainability [5]. 
As shown by the review findings, there is also a need of to investigate and outline mechanisms for a cooperation between the public health institutions and the legal sector to minimize confusions in the current public health legislation [1]. New structural reforms implemented in practice, not just stipulated in the legislation, can help to place priority on the public health actions. Rural health centers, as well as the KAPIs in the urban areas, could be integrated as mechanisms for the enhancement of public health and prevention policies [2]. Public health actions in Greece also need to become cross-sectoral to assure that the health determinants are adequately addressed. These general policy recommendations are equally relevant when health promotion policies for elderly persons are the specific subject of policy discussions in Greece.

\section{References}

1. Hatzianastasiou S., Pavli A., Maltezou H.C., Legal aspects of public health: How law frames communicable disease control in Greece, "Journal of Public Health" 2011; 32 (4): 445-457.

2. Economou C., Greece: Health system review, "Health Systems in Transition" 2010; 12 (7): 1-180, http://www. euro.who.int/_data/assets/pdf_file/0004/130729/e94660. pdf?ua $=1$; accessed: 8.06.2016.

3. Greek Ministry of Health, Greece country review. JACHRODIS - Good Practice in the Field of Health Promotion and Primary Prevention, 2014, http://www.chrodis.eu/ wp-content/uploads/2014/10/JA-CHRODIS_Greece-country-review-in-the-field-of-health-promtion-and-primaryprevention.pdf; accessed: 8.06.2016.

4. Tountas Y., Karnaki P., Pavi E., Reforming the reform: the Greek national health system in transition, "Health Policy" 2002; 62 (1): 15-29.

5. Sourtzi P., Roka V., Velonaki V., Kalokerinou A., Health Promotion Programs for the Elderly in Greece, the "Health Pro Elderly" Project, "Hygiea Internationalis" 2010; 9 (1): 385-395, http://www.ep.liu.se/ej/hygiea/v9/i1/a18/hygiea10v9i1a18.pdf; accessed: 8.06.2016.

6. Sørensen K., Pelikan J.M., Röthlin F., Ganahl K., Slonska Z., Doyle G. et al., Health literacy in Europe: comparative results of the European health literacy survey (HLS$E U)$, "European Journal of Public Health" 2015; 25 (6): 1053-1058.
7. Argyropoulos K., Bartsokas C., Argyropoulou A., Gourzis P., Jelastopulu E., Depressive symptoms in late life in urban and semi-urban areas of South-West Greece: An undetected disorder?, "Indian Journal of Psychiatry" 2015; 57 (3): 295-300.

8. Mamplekou E., Bountziouka V., Psaltopoulou T., Zeimbekis A., Tsakoundakis N., Papaerakleous N. et al., Urban environment, physical inactivity and unhealthy dietary habits correlate to depression among elderly living in eastern Mediterranean islands: The MEDIS (MEDiterranean ISlands Elderly) study, "The Journal of Nutrition, Health \& Aging" 2010; 14: 449-455.

9. Pappa E., Kontodimopoulos N., Papadopoulos A.A., Tountas Y., Niakas D., Prescribed-drug utilization and polypharmacy in a general population in Greece: association with sociodemographic, health needs, health-services utilization, and lifestyle factors, "European Journal of Clinical Pharmacology” 2011; 67 (2): 185-192.

10. Ifanti A.A., Argyriou A.A., Kalofonou F.H., Kalofonos H.P., Financial crisis and austerity measures in Greece: their impact on health promotion policies and public health care, "Health Policy" 2013; 113: 8-12.

11. Karanikolos M., Mladovsky P., Cylus J., Thomson S., Basu S., Stuckler D. et al., Financial crisis, austerity, and health in Europe, "Lancet" 2013; 381 (9874): 1323-1331.

12. IKA, Clinic of Preventive Medicine for Adult, 2016, https:// www.ika.gr/gr/infopages/healthservices/proliptiki.cfm; accessed: 8.06.2016.

13. Kryńska E., Szukalski P., Active ageing measures in selected European Union countries. Final report, 2013, http:// zielonalinia.gov.pl/upload/50plus/Raport-koncowy/Raportkoncowy-50-plus-eng.pdf; accessed: 8.06.2016.

14. Ponirou P., Diomidous M., Kalokairinou A., Mantas J., Tsimahidou C., Tzavara C., Health related quality of life in a sample of older people who are members of Open Care Centers for the Elderly, "Studies in Health Technology and Informatics" 2014; 202 (Integrating Information Technology and Management for Quality of Care): 269-272.

15. Mariolis A., Foscolou A., Tyrovolas S., Piscopo S., Valacchi G., Tsakountakis N. et al., Successful aging among elders living in the Mani Continental Region vs. Insular Areas of the Mediterranean: the MEDIS Study, "Aging and Disease" 2016; $27: 7$ (3): 285-294. 